\title{
DAYA TARIK BUNGA SAKURA BAGI MASYARAKAT JEPANG
}

\author{
Nur Hastuti \\ Program Studi Bahasa dan Sastra Jepang FIB Universitas Diponegoro \\ Email: nuha_chan@yahoo.com
}

\begin{abstract}
Sakura is the pride flower of Japanese from the past. Many person can enjoy the beauty of Sakura. Sakura usually blossoms in the spring season, begins from south Japan region in the middle of March and continue to the norh Japan (in the middle of April up to end of April). During spring season, mass media reports about Zensen Sakura, that is prediction the growth of Sakura in many places in Japan, along with climate prediction. By that information, Japanese people are ready to welcome warmer air in the spring (after winter) and holding Hanami feast. Based on that situation, writer interest to write this research by the title " The Attraction of Sakura Flower for Japanese people". The problem that will be analized is how is the attraction and the effect of Sakura flower for Japanese people. In this research, writer uses literary review from internet, article, and many other sources. The attraction of Sakura flower is Japanese people can enjoy Hanami with family, friends, and close person in the office and organization. The effect of Sakura in Japanese life is very important, like to raise the affection in the family, make closer the friendship, and make better communication with partner or relation.
\end{abstract}

Keywords: hanami, sakura zensen, attraction, feast, sakuramochi

\section{PENDAHULUAN}

Jika mendengar kata sakura pasti yang terlintas dalam pikiran kita adalah negeri Jepang. Di Jepang sakura adalah bunga yang menjadi kebanggaan masyarakatnya sejak zaman dulu. Bunga sakura selain dinikmati dengan mata oleh banyak orang, ternyata daun dan buahnya dapat juga dimakan. Bunga sakura biasanya mekar pada saat musim semi, dimulai dari daerah Jepang bagian selatan pada pertengahan Maret, kemudian terus menjalar ke bagian utara (pertengahan sampai akhir bulan April). Selama musim semi media massa Jepang ramai melaporkan sakura zensen, yaitu ramalan munculnya bunga sakura di berbagai tempat di Jepang, bersamaan dengan ramalan cuaca. Dengan adanya informasi tersebut, masyarakat Jepang dapat bersiap-siap menyambut udara yang lebih hangat di musim semi (setelah musim dingin) dan mengadakan pesta hanami ${ }^{1}$.
Pentingnya bunga sakura dalam kehidupan masyarakat Jepang dapat terlihat dari pemakaian bunga ini dalam berbagai hal misalnya dipakai untuk motif pakaian, untuk dekorasi kerajinan seni, dll. Hal tersebut tidak mengherankan jika Jepang dijuluki sebagai "Negeri Sakura". Sakura merupakan salah satu pohon yang tergolong dalam familia Rosaceae dalam genus Prunus, yaitu sejenis dengan pohon prem, persik atau aprikot. Adapun asal usul kata "sakura" adalah "saku", ditambah dengan akhiran yang menyatakan bentuk jamak"ra". Dalam bahasa Inggris, bunga ini disebut cherry blossoms.

\section{RUMUSAN MASALAH}

Berdasarkan uraian di atas, permasalahan yang penulis bahas adalah

1. Bagaimana daya tarik bunga sakura bagi masyarakat Jepang?

2. Apa saja pengaruh bunga sakura bagi masyarakat Jepang?

${ }^{1}$ Melihat bunga sakura

${ }^{2}$ Mekar

Jurnal Izumi, Volume 5, No 1, 2015 


\section{PEMBAHASAN}

Pada zaman kuno, bunga sakura yang umum ditemukan adalah bunga sakura yang mekar di gunung yang disebut Yamasakura, namun pada masa Edo berkembang sakura jenis Someiyoshino yang menyebar ke setiap daerah di Jepang. Di Jepang, mekarnya sakura jenis someiyoshino dimulai dari Okinawa di bulan Februari, dilanjutkan di pulau Honshu bagian sebelah barat, sampai di Tokyo, Osaka, Kyoto pada sekitar akhir Maret sampai awal April, lalu bergerak sedikit demi sedikit ke utara, dan berakhir di $\underline{\text { Hokkaido di saat liburan Golden Week }}{ }^{3}$.

\subsection{Sejarah Sakura}

Sakura pertama kali muncul dalam karya sastra Jepang yaitu Kojiki ${ }^{4}$ dan NihonShoki ${ }^{5}$ lewat tokoh Kono Hana Sakuya Hime, yaitu putri Dewa Gunung. Dikisahkan dalam Nihon-Shoki bahwa putrid Kono Hana Sakuya Hime naik ke atas kabut dan terbang ke atas langit gunung Fuji, dari atas gunung Fuji dia menaburkan benih bunga. Bunga yang disebarkan itu diberi Sakura(diambil dari nama Sakuya dan menjadi nama Sakura). Adapun di dalam Kojiki dikisahkan bahwa putrid tersebut turun dari langit lewat sebuah gunung api, yang letaknya diperbatasan daerah Miyazaki dan Kagoshima, lalu menjadi istri Ninigi no Mikoto (cucu dewa matahari), dalam kojiki disebut bahwa Sakuya berarti bunga Sakura itu sendiri. ${ }^{6}$

\subsection{Jenis Bunga Sakura}

Bunga Sakura memiliki berbagai varian jenis pohon. Sebagian besar jenis pohon sakura merupakan hasil persilangan, misalnya jenis someiyoshino yang tersebar di seluruh Jepang sejak zaman Meiji adalah hasil persilangan pohon sakura di akhir zaman Edo. Sakura jenis someiyoshino

\footnotetext{
${ }^{3}$ periode di akhir bulan April hingga minggu pertama bulan Mei di Jepang yang memiliki serangkaian hari libur resmi

${ }^{4}$ Buku sejarah dan mitologi Jepang yang disusun pada tahun 712

${ }^{5}$ Buku sejarah Jepang yang disusun pada tahun 720

6 _.2003. Kedutaan Besar Jepang:Aneka Jepang.Jakarta Pusat
}

inilah yang banyak tersebar luas, sehingga kebanyakan orang hanya mengenal someiyoshino (yang merupakan salah satu jenis sakura) sebagai sakura. Sakura jenis someiyoshino memiliki ciri khas sendiri dibandingkan dengan bunga sakura yang lain yaitu, bunganya yang lebih dahulu mekar sebelum daun-daunnya mulai keluar, dan bunganya mulai mekar secara serentak dan rontok satu per satu pada saat yang hampir bersamaan. Bunga sakura jenis someiyoshino ini hanya dapat bertahan kurang lebih 7 sampai 10 hari dihitung mulai dari kuncup bunga terbuka hingga bunga mulai rontok. Rontoknya bunga sakura tergantung pada keadaan cuaca dan biasanya dipercepat oleh hujan lebat dan angin kencang. Beberapa jenis burung dikenal suka memakan bagian bunga ini yang berasa manis, sedangkan burung merpati memakan seluruh bagian bunga. Pada zaman dulu sebelum ada jenis someiyoshino, orang Jepang mengenal bunga sakura yang mekar di pegunungan dengan nama yamazakura dan yaezaki no sakura sebagai sakura. Di saat mekarnya bunga sakura, ribuan batang pohon Yamazakura yang tumbuh di Pegunungan Yoshino (Prefektur Nara) menciptakan pemandangan menakjubkan warna putih, hijau muda, dan merah jambu ${ }^{7}$. Tidak mengherankan jika bunga sakura disanjung banyak orang tidak hanya oleh masyarakat Jepang namun juga wisatawan asing yang berkunjung ke Jepang karena keindahannya.

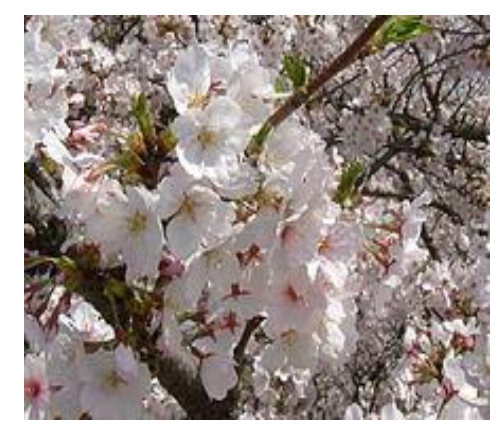

Bunga Sakura Someiyoshino

Adapun beberapa jenis dari bunga sakura adalah sebagai berikut:

\footnotetext{
${ }^{7}$ http://id.wikipedia.org/wiki/Sakura
} 


\section{Edohigen}

Edohigen adalah sakura yang mekar di Hari Ekuinoks ${ }^{8}$. Jenis-jenis lain yang serupa dengan edohigan adalah ishiwarizakura dan yamadakashinyozakura yang termasuk pohon sakura yang dilindungi. Miharutakizakura adalah salah satu jenis edohigan yang rantingnya menjuntai-juntai, sedangkan yaebenishidare dikenal daun bunganya yang banyak dan warnanya yang cerah.

\section{Hikanzakura}

Bunga sakura ini banyak tumbuh di daerah Okinawa dan pulau Honshu. Di Okinawa, kuncup bunga hikanzakura mulai terbuka sekitar bulan Januari atau Februari. Adapun di Pulau Honshu, hikanzakura banyak ditanam mulai dari wilayah Kanto sampai ke Kyushu dan biasanya mulai mekar sekitar bulan Februari atau Maret dan lain-lain.

Bagi orang Jepang, bunga Sakura merupakan simbol penting yang sering diasosiasikan dengan perempuan, kehidupan, kematian, sehingga bunga Sakura dapat ditemukan di mana saja di Jepang. ${ }^{9}$ Sakura diasosiasikan sebagai perempuan karena perempuan laksana bunga yang yang cantik nan indah dipandang bagaikan bunga sakura yang mekar membawa ketenangan dan kebahagiaan. Hal ini menunjukkan bahwa sakura adalah bunga penting dalam kehidupan orang Jepang, dimana semua orang memujanya saat mekar, setelah mereka (masyarakat Jepang) melewati musim dingin yang berat. Jika sakura dilambangkan dengan kematian karena tumbuh dan mekarnya bunga sakura yang indah hanya sebentar kira-kira seminggu sampai 10 hari saja. kemudian bunga sakura akan layu berguguran tertiup angin, mati lalu hilang. Hal ini melambangkan bahwa kehidupan manusia itu seperti bunga sakura yang begitu singkat, yaitu mekar (lahir), hidup lalu mati.

\footnotetext{
${ }^{8}$ titik Musim Semi Matahari menandai dimulainya musim semi astronomis.

${ }^{9}$ http://news.liputan6.com/read/2214408/melihatbunga-sakura-yang-tumbuh-di-batam
}

\subsection{Daya Tarik Bunga Sakura}

\subsubsection{Hanami}

Hanami sebenarnya merupakan sebuah ritual religius yang diadakan pada hari tertentu di musim semi, yakni upacara menjelang dilakukan pekerjaan tanammenanam. Penuhnya bunga-bunga sakura berjuntai dari pohon-pohonnya konon dianalogikan dengan panen padi yang berlimpah, yang harus dirayakan dengan makan dan minum. Akan tetapi di masa lampau, hanami hanya dilakukan oleh kaum bangsawan dan penguasa saja, baru pada akhir abad ke-17 kebiasaan itu dilakukan oleh rakyat biasa.

Semula acara hanami merupakan pesta di udara terbuka untuk menikmati bunga pohon aprikot Jepang (ume). Sebelum masa Heian, banyak orang memberikan apresiasi pada bunga sakura liar yang berada di gunung. Ketika masa Heian (794-1192), bunga sakura dipindahkan ke dalam kota kerajaan dan dapat dinikmati bersama.Kebiasaan hanami berawal dari kaisar pada masa itu yang mengadakan acara jamuan di halaman istananya yang ditanami dengan bunga sakura. Setelah itu, kebiasaan ini meluas dari kalangan istana kepada kalangan Bushi/Samurai dan rakyat biasa, lalu tersebar dari kota kerajaan ke daerah lainnya di Jepang.

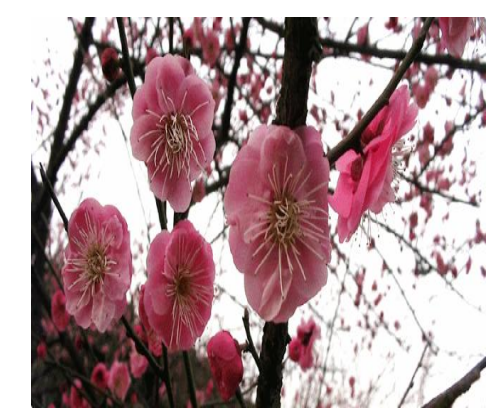

Bunga Pohon Ume

Hanami adalah $\begin{array}{r}\text { moment } \\ \text { orang-orang }\end{array}$
membahagiakan bersama menikmati
tersayang dan terdekat untuk menian
indahnya bunga sakura yang mekar. Hal ini
berarti Mekarnya bunga sakura merupakan
lambang kebahagiaan telah tibanya musim
semi. Selain itu, hanami juga berarti piknik
dengan menggelar tikar untuk pesta makan-
makan di bawah pohon sakura. Rombongan
demi rombongan berpiknik menggelar tikar
dan duduk-duduk di bawah pepohonan


sakura untuk bergembira bersama, minum sake, makan makanan khas Jepang, dan lainlain layaknya pesta kebun. Semuanya bergembira. Ada kelompok keluarga, ada kelompok perusahaan, organisasi, sekolah dan lain-lain.

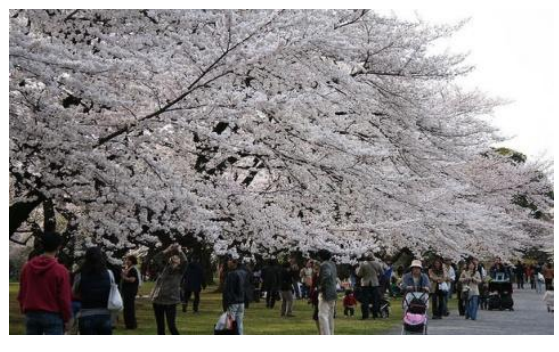

Menikmati Hanami

Munculya bunga sakura juga menandai mulainya tahun pelajaran baru untuk sekolah dan berakhirnya tahun fiskal yang lama dan mulainya tahun fiskal yang baru bagi dunia keuangan dan dunia usaha. Hal ini menunjukkan bahwa mekarnya bunga sakura membawa semangat baru untuk menggapai harapan dan keinginan yang baik.

Menurut Telegraph, tempat paling baik di Jepang untuk menikmati Hanami adalah Nagoya Castle, Kumamoto Castle, taman Shinjuku Gyoen, Hirosaki Castle, Osaka Castle, taman Ueno, taman Inogashira, Kamagatani, Pinggir sungai Shinsakai, Pegunungan Yoshino dan masih banyak lainnya. ${ }^{10}$ Adapun beberapa contoh dari tempat indah tersebut untuk hanami adalah sebagai berikut.

\section{Shinjuku Gyoen}

Shinjuku Gyoen (144 hektar) adalah sebuah taman yang besar dekat Shinjuku. Taman ini memiliki 1.500 pohon sakura. Taman ini cukup besar untuk dapat menemukan tempat dan menikmati hanami bersama-sama. Taman ini luas, sehingga dapat digunakan untuk mengadakan Hanami dengan skala besar. Taman ini juga memliki banyak jenis bunga Sakura yang indah.

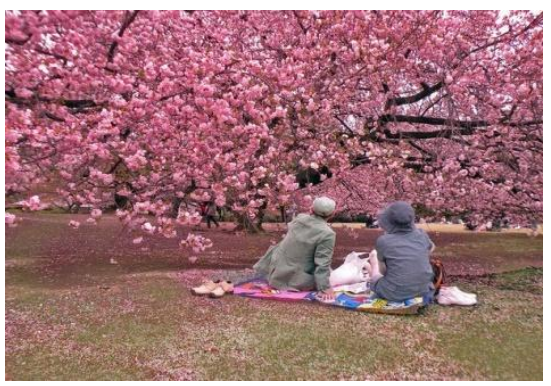

Shinjuku Gyoen

\section{Taman Ueno}

Taman Ueno (133 hektar) adalah tempat untuk mengadakan pesta Hanami dalam skala besar. Biasanya tempat ini sangat ramai sekali dan memiliki sekitar 1000 pohon sakura ditambah dengan kolam Shinobazu yang sangat indah. Pohon Sakura di taman ini termasuk yang lebih dahulu mekar di Tokyo.

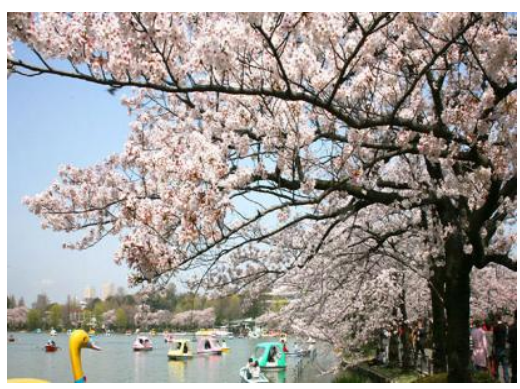

Taman Ueno

\section{Taman Inogashira}

Sebuah taman besar (95 hektar) dengan 1000 pohon sakura. Taman ini banyak dikunjungi oleh mahasiswaamahasiswa. Juga popular bagi pasangan kekasih untuk menikmati pemandangan dari kolam dengan menggunakan perahu angsa.

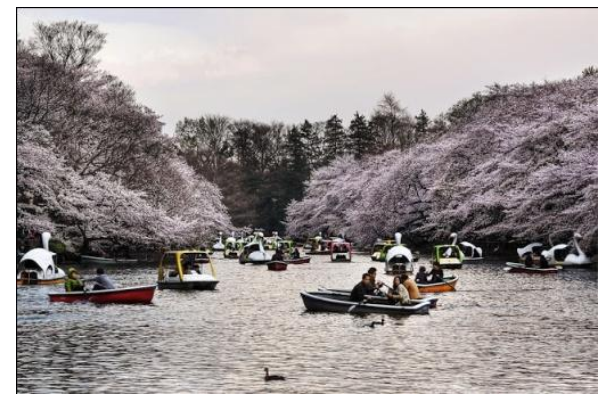

Taman Inogashira 
Berbagai daerah di Jepang juga menyelenggarakan festival bunga sakura dengan tradisi masing-masing dari bulan Maret sampai Mei. Waktu penyelenggaraannya pun berlainan karena mekarnya bunga sakura di tiap daerah juga berbeda-beda. Adapun contoh tempat festival bunga sakura adalah sebagai berikut.

\section{Festival Bunga Sakura di Benteng Himeji}

Benteng Himeji adalah benteng terbesar di Jepang. Di sekitar kompleks benteng yang disebut-sebut sebagai salah satu benteng tertua dan terindah di Jepang diperkirakan terdapat sekitar 1.000 sakura. Untuk merayakannya diadakan festival selama tiga hari yang meliputi pertunjukan drum dan gendang khas Jepang, upacara minum teh, dan festival jajanan khas musim semi.Meskipun tidak pernah diadakan dalam waktu yang sama setiap tahunnya, biasanya sebelum memulai festival ini pihak pengelola taman Benteng Himeji akan membuat pengumuman terlebih dahulu. Biasanya pihak pengelola juga membuka taman bagi masyarakat yang berniat memandang bunga sakura pada malam hari.

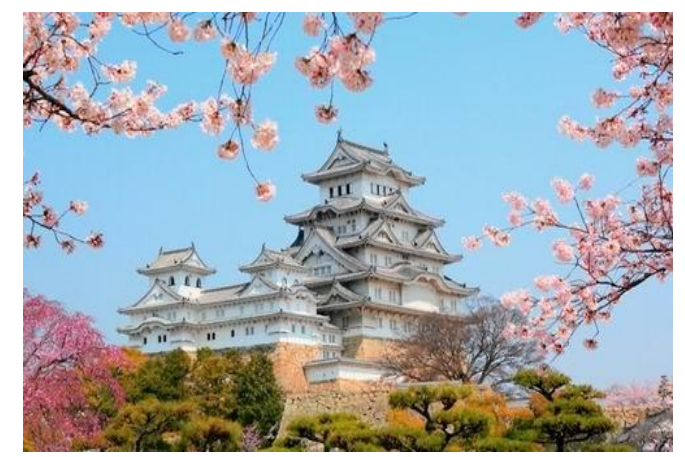

2. Festival Bunga Sakura di Kitakami Tenshochi

Festival Bunga Sakura Kitakami Tenshochi berlangsung di kota Kitakami, Prefektur Iwate, bagian utara Pulau Honshu, Jepang. Festival bunga sakura di daerah ini berlangsung lebih lama daripada Benteng Himeji. Biasanya sekitar tiga minggu. Rangkaian acara dalam festival musim semi ini meliputi wisata perahu menyusuri Sungai Kitakami, piknik di tepian sungai, dan memandang bunga sakura di malam hari dengan pencahayaan dari lampion-lampion. Pengunjung juga bisa menikmati pemandangan bunga sakura dengan mengendarai kereta kuda melewati deretan pepohonan sakura yang tumbuh di sepanjang pinggiran sungai dengan harga yang cukup terjangkau.

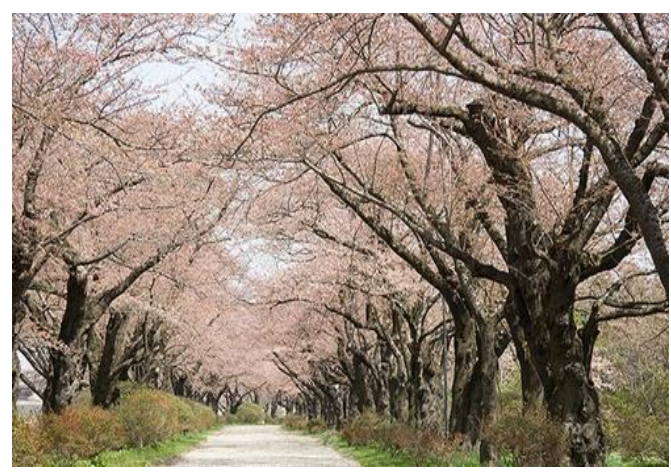
3. Festival Bunga Sakura di
Matsumae Koen

Festival bunga sakura ini diadakan di Kota Matsumae, Prefektur Hokkaido, Jepang. Jika dibandingkan dengan Honshu, musim bunga sakura di Hokkaido datang lebih lambat, dimulai dari akhir April. Di kota ini ada dua tempat yang bisa dituju jika ingin melakukan hanami, yaitu Matsumae Koen dan Goryokaku Koen. Namun tempat yang paling popular dikunjungi adalah Matsumae Koen. Sama seperti Taman Tenshochi, taman ini juga termasuk dalam seratus tempat terbaik untuk memandang bunga sakura di Jepang. Di sana terdapat kurang lebih 10.000 pohon sakura dari 250 spesies. Pohon-pohon tersebut tumbuh di sekitar Benteng Matsumae. Festival ini berlangsung cukup lama, mulai akhir April sampai akhir Mei karena ratusan jenis sakura di Matsumae Koen memang bermekaran pada waktu yang berbeda.

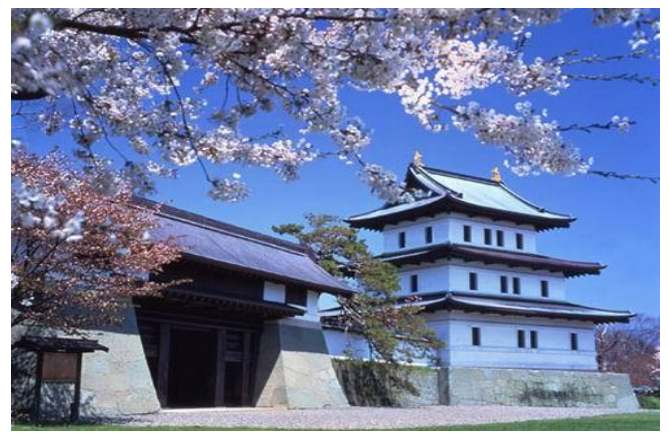




\subsubsection{Sakuramochi}

Sakuramochi adalah kue mocha dari beras ketan yang dibungkus dengan sebuah daun sakura yang sudah di frementasikan terlebih dahulu dengan larutan garam. Cita rasa daun sakura dan garam menyerap ke dalam beras ketan. Dengan kombinasi rasa manis kacang merah yang dihaluskan di dalamnya, kue ini sungguh menawan. Kue ini tidak dapat dipisahkan dengan musim bunga sakura di Jepang.

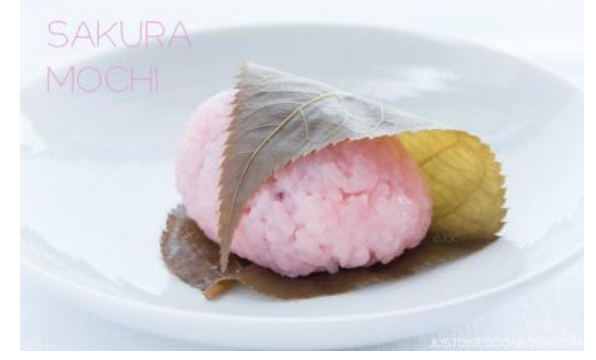

\subsubsection{Puisi}

Di dalam Manyoshu, buku kumpulan puisi Jepang yang disusun lebih dari 1.200 tahun yang lalu, bunga sakura juga ditampilkan sebagai bunga di musim semi. Berikut ini adalah contoh puisi di antara beberapa puisi tentang sakura dalam Manyoshu.

\section{さくらさばな \\ Sakurabana \\ いまぞらさかりと \\ Imazosakarito \\ ひとわいえど \\ Hitowaiedo \\ われわさぶしも \\ Warewasabushimo \\ きみとしあらねば \\ Kimitoshiaraneba}

Artinya meskipun orang bilang bunga sakura saat ini sedang mekar, aku merasa sepi karena dirimu tiada.
Bunga sakura telah melekat dalam hati orang Jepang, hal tersebut terlihat dimana bunga sakura dipuji, dicintai oleh masyarakat Jepang karena keindahan dan kecantikannya. Tidak mengherankan jika banyak penyair yang menyusun lirik sambil mengenang keluarga, kekasih dan orangorang terdekat sambil melihat dan menikmati bunga sakura yang mekar serta menuliskan karyanya seperti pada salah satu contoh puisi di atas mengenai bunga sakura.

Ternyata bunga sakura yang muncul pada musim semi membawa pengaruh sangat penting dalam kehidupan orang Jepang, seperti mempererat kasih sayang bersama keluarga, mengakrabkan persahabatan, menjalin komunikasi yang baik dengan rekan/mitra kerja peusahaan dan lain-lain. Usianya yang pendek dan kerapuhannya membawa arti yang mendalam bagi kehidupan.

\section{SIMPULAN}

Bunga sakura merupakan bunga nasional Jepang, yang kedatangannya selalu dinanti saat musim semi. Bunga sakura yang mekar muncul serentak merimbuni seluruh pohon menambah keindahan bunga sakura. Daya tariknya menghipnotis sehingga membuat masyarakat Jepang ataupun wisatawan asing tidak ingin melewati moment indah saat bunga sakura mekar, seperti perayaan pesta Hanami dan menikmati kue sakuramochi. Pengaruh bunga sakura sangat penting bagi masyarakat Jepang seperti mempererat kasih sayang bersama keluarga, mengakrabkan persahabatan, menjalin komunikasi yang baik dengan rekan/mitra kerja perusahaan dan lain-lain. 


\section{DAFTAR PUSTAKA}

.2009. Kedutaan Besar

Jepang:Aneka Jepang.Jakarta Pusat https://cankir.wordpress.com/2010/1 0/25/kebudayaan-jepang/ https://id.wikipedia.org/wiki/Sakura mochi

https://id.wikipedia.org/wiki/Many\% C5\%8Dsh\%C5\%AB

http://www.justonecookbook.com/sa kura-mochi/

http://japanesestation.com/7-festivalbunga-sakura-paling-meriah/
http://id.wikipedia.org/wiki/Sakura http://www.bbc.com/indonesia/multi media/2015/03/150330_galeri_sakur a

https://www.maxmanroe.com/hiduphanya-sesingkat-sakura.html https://id.wikipedia.org/wiki/Minggu _Emas_\%28Jepang\%29 https://id.wikipedia.org/wiki/Ekuino ks_vernal 